\title{
AÇÕES EDUCATIVAS PARA O COMBATE AO MOSQUITO AEDES AEGYPTI EM UMA ESCOLA DA REGIÃO METROPOLITANA DE SÃO LUÍS
}

\author{
Marcos Eduardo Miranda Santos ${ }^{1}$, Wanda dos Santos Batista ${ }^{1}$, João Victor França Oliveira ${ }^{1}$, \\ Isabel Conceição Carvalho Jansen ${ }^{1}$, Kelly Fernanda de Sousa Santos ${ }^{1}$, \\ Eliane Coelho Rodrigues dos Santos ${ }^{2}$
}

Resumo: $\mathrm{O}$ presente trabalho teve por objetivo realizar ações educativas para o combate do mosquito Aedes aegypti com alunos de uma escola de ensino fundamental do município de São Luís - MA. Para isso, realizou-se pesquisa-ação na Escola Raio de Sol (São Luís, MA). A intervenção consistiu na aplicação de um diagnóstico ambiental, atividades práticas e exibição de vídeos educativos. Percebeu-se o maior interesse dos alunos em aulas práticas e metodologias alternativas, as quais demonstraram ser mais eficientes no processo de conscientização e sensibilização dos alunos. Portanto, essas metodologias devem ser incentivadas para que a educação possa contribuir no combate do mosquito dentro e fora do ambiente escolar.

Palavras-chave: Aedes aegypti. Educação. Ensino Fundamental.

\section{EDUCATIONAL ACTIONS FOR FIGHTING THE MOSQUITO AEDES AEGYPTI IN A SCHOOL IN THE METROPOLITAN REGION OF SÃO LUÍS}

\begin{abstract}
Abstrac: The present work aimed to carry out educational actions to combat the Aedes aegypti mosquito with students from a primary school in the city of. For this, action research was carried out at the Sun Ray School (São Luis, MA). The intervention consisted in the application of an environmental diagnosis, practical activities and the exhibition of educational videos. Students were more interested in practical classes and alternative methodologies, which proved to be more efficient in the process of raising awareness and awareness among students. Therefore, these methodologies should be encouraged so that education can contribute to the fight against mosquitoes inside and outside the school environment.
\end{abstract}

Keywords: Aedes aegypti. Education. Elementary School.

1 Graduando do curso de Ciências Biológicas Licenciatura da Universidade Estadual do Maranhão.

2 Mestre em Saúde e Ambiente. Docente da Universidade Estadual do Maranhão. 


\section{INTRODUÇÃO}

O mosquito transmissor da Dengue, Zika e Chikungunya, dentre outras viroses é originário da África (CHIARAVALLOTI-NETO, 1997; GOMES, 1998) e tem preferência pelas regiões tropicais e subtropicais do planeta (REBÊLO et al., 1999). Denominado inicialmente como Culex aegypti em 1762, foi renomeado para Aedes aegypti em 1818. Segundo relatos da Organização Pan-Americana de Saúde (OPAS), a primeira epidemia de doenças causada pelo $A$. aegypti no continente americano ocorreu no Peru, no início do século XIX, tendo surto no Caribe, Estados Unidos, Colômbia e Venezuela (IOC/FIOCRUZ, 2016).

$\mathrm{O} A$. aegypti chegou ao Brasil no final do século XIX através de navios negreiros e foi a partir desse evento que foram introduzidas as doenças transmitidas por esse vetor (VASCONCELOS, 2015). Além disso, estudos realizados por Bryant et al., (2007) confirmam que "o mosquito coincide com as grandes navegações e o tráfico de escravos".

Os primeiros casos de doenças causadas pelo mosquito no país foram em Curitiba (PR), no século XIX e em seguida em Niterói (RJ), no século XX (BRAGA; VALLE, 2007; IOC/FIOCRUZ, 2016), mas a primeira epidemia relacionada ao mosquito ocorrida no Brasil foi a de febre amarela, em Recife no ano de 1685 (COSTA, 2001). Nessa época a preocupação em eliminar o vetor estava relacionada com essa doença (LIMA, 1985). Então em 1691, na cidade de Recife, ocorre a primeira campanha sanitária contra o A. aegypti (COSTA, 2001). Segundo Chiffi (1985, p. 385), "a erradicação do $A$. aegypti tornou-se um dos objetivos nacionais através do Decreto no 8.675 , de 4/2/1942, já era, desde 1934, extraoficialmente, umas das finalidades precípuas do serviço de combate à febre amarela.

A preocupação em erradicar o mosquito nas Américas deu-se na década de 1940, pela Fundação Rockefeller, onde a mesma obteve grande sucesso. Em 1947, a Organização Pan-Americana da Saúde (OPAS) e a Organização Mundial de Saúde (OMS) resolveram coordenar a erradicação do vetor e no final da década de 50 o mosquito foi erradicado de quase toda a América (AZEVEDO, 2015). O vetor foi erradicado duas vezes no país, porém em 1976, as medidas de controles foram relaxadas, o que levou a reinfestação do vetor no território brasileiro (LIMA, 1985). Conforme afirma Lima (1985, p. 378) "a partir de 1976, começaram a ocorrer sucessivas reinfestações, a partir de países vizinhos da América Latina [...], o que, associado à crônica e falta de recursos para combatê-los, permitiu a expansão do vetor a extensas áreas do território nacional” o que gerou novamente uma grande preocupação. Gomes (1998, p. 50) afirma que, “o Brasil conseguiu erradicar o A. aegypti de seu território, mas não impediu a sua reinfestação posterior" e com isso, hoje o mosquito é encontrado em todos os Estados brasileiros (LIMA, 1985; GOMES, 1998; IOC/FIOCRUZ, 2016).

No ano de 1908 foram descritas as primeiras características do Aedes aegypti, e foi nesse contexto que Antônio Gonçalves Peryassú, pesquisador do Instituto Soroterápico 
Federal, hoje o Instituto Oswaldo Cruz (IOC) fez as descobertas sobre o ciclo de vida, os hábitos e a biologia do A. aegypti (IOC/FIOCRUZ, 2016).

$\mathrm{O} A$. aegypti é encontrado, principalmente, no meio urbano, colonizando depósitos de armazenamento de água e pequenas coleções temporárias (TAKAHASHI et al., 2003). É um mosquito comum que se prolifera com facilidade no ambiente doméstico, pois não existem predadores para eliminá-los da natureza, além disso, há uma grande disponibilidade de criadouros (CHIEFFI, 1985; TAKAHASHI et al., 2003), o que facilita sua multiplicação. As fêmeas põem os ovos dentro de qualquer recipiente com água limpa dos quais surgem às larvas, que por sua vez se transformam em pupas que irão se desenvolver e futuramente tornar-se um mosquito adulto. $\mathrm{O}$ tamanho dos mosquitos adultos varia de acordo com a temperatura e a disponibilidade de alimento (sangue humano) (TAKAHASHI et al., 2003).

Hoje o $A$. aegypti vem transmitindo novas doenças no Brasil decorrente do fluxo de turistas vindo de outros países. Além disso, de acordo com Vasconcelos (2015) no Brasil a introdução e um rápido processo de dispersão rumo célere ao endemismo de dois novos arbovirus para as Américas, mas que são velhos conhecidos na África e Ásia: o vírus Chikungunya, introduzido em julho/agosto de 2014 e o vírus Zika, possivelmente introduzido na Copa do Mundo em 2014 (VASCONCELOS, 2015).

Conforme afirma Brassolatti e Andrade (2002, p. 244) "em todos os países, são muitas as intervenções educativas voltadas para os problemas de saúde pública" Nesse contexto, por se tratar de saúde pública, devido esse vetor ser causador de diversas arbovirose (VASCONCELOS, 2015), a educação se torna fundamental uma vez que, através dela as pessoas adquirem os conhecimentos necessários para o desenvolvimento e medidas contra o mosquito (BRASSOLATTI; ANDRADE, 2002). E ainda segundo Costa (2008, p. 31) "uma forma de promover saúde e incentivar práticas de vida saudáveis é utilizar-se do processo de educação em saúde, onde se oportuniza o compartilhamento de saberes dos mais variados possíveis na busca de soluções das mais diversas problemáticas". Dessa maneira, objetivou-se realizar ações educativas para o combate do mosquito Aedes aegypti com alunos de uma escola de ensino fundamental do município de São Luís - MA.

\section{METODOLOGIA}

\section{1 Área de estudo}

O projeto foi aplicado na Escola Raio de Sol, localizada na Rua Três, Planalto Pingão, São Luís, MA. Essa escola pertence à rede privada de ensino e atende a alunos do Ensino Fundamental Menor ( $1^{\circ}$ ao $4^{\circ}$ ano), no período matutino, e ao Ensino Fundamental Maior (5 ao $9^{\circ}$ ano) no período vespertino. 


\subsection{Metodologia aplicada}

Este trabalho baseou-se na metodologia da Pesquisa-ação. Essa metodologia implica o desenvolvimento de estudos junto a grupos sociais, nos quais é necessário que o pesquisador tenha compromisso com o grupo pesquisado a fim de buscarem a resolução de problemas de um problema coletivo (OLIVEIRA, 2007).

A ação foi realizada com os alunos do $7^{\circ}$ ano do ensino Fundamental, pois nesse ano se trabalha o conteúdo vírus e as doenças causadas por eles. Inicialmente realizouse o diagnóstico da percepção dos alunos através da aplicação de um questionário semiestruturado, a fim de diagnosticar quais os conhecimentos prévios que os alunos possuíam sobre o tema. Os dados foram tabulados e colocados em planilhas do Excel para construção de gráficos.

Após a apresentação do projeto e realização do diagnóstico, foi realizada a conscientização dos alunos através de duas ações: 1) Apresentação de vídeo didático e 2) Atividade prática para observação da morfologia do mosquito em microscópios.

\section{RESULTADOS E DISCUSSÃO}

\subsection{Diagnóstico da percepção dos alunos}

Quando perguntados sobre o nome do mosquito que transmitia as doenças Dengue, Zika e Chikungunya, 97\% dos alunos marcaram a alternativa Aedes aegypti, $2 \%$ marcaram Aedes áureos e 1\% marcou que não sabia (FIGURA 1). "O Aedes aegypti é o principal vetor da dengue, febre amarela, febre chikungunya e febre zika"(NUNES, 2015 , p.7). Observou-se que a maioria dos alunos tinha o conhecimento que o mesmo mosquito poderia transmitir as três doenças, posteriormente, com a exposição de vídeo e explicações, essa informação foi reforçada a fim de sanar as dúvidas dos alunos, que não tinham conhecimento sobre a forma de transmissão. 
Figura 1 - Identificação do mosquito transmissor da Dengue, Zika e Chikungunya

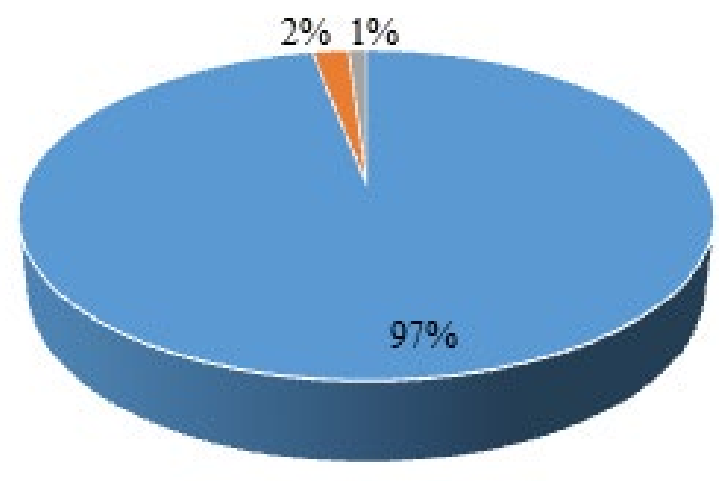

" Aedes aegypti "Aedes cureos "Não sei

Fonte: dos autores.

Também foi perguntado se uma pessoa infectada por dengue pode transmitir para outra, onde $53 \%$ dos alunos marcaram sim, $41 \%$ dos alunos marcaram não e $6 \%$ marcaram que não tinham conhecimento a respeito desse questionamento (FIGURA 2). Os relatos de casos sugerem que as consequências da dengue durante a gravidez para a gestante e para o concepto dependem da severidade da doença e do período gestacional em que a infecção ocorre (POULIOT et al., 2010). Essa questão ainda não é consenso entre os cientistas. É necessária a realização de mais pesquisas para se chegar a uma conclusão definitiva. 
Figura 2 - Transmissão entre pessoas infectadas

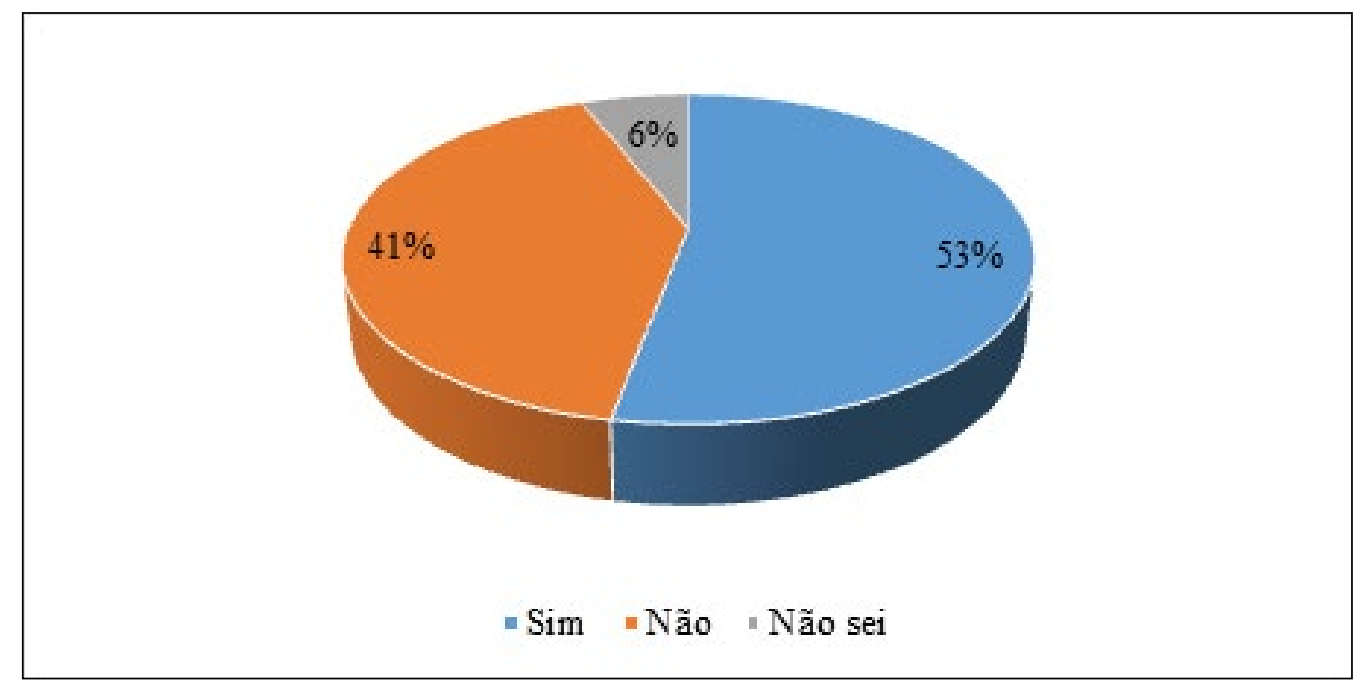

Fonte: dos autores.

O terceiro questionamento estava associado aos possíveis criadouros dos mosquitos. As categorias com o maior número de marcação foram caixa d'água sem tampa (94\%), pneus velhos (93\%) e garrafas vazias (72\%). As demais foram casa com calha no telhado (55\%), vasos com flores (56\%), água dentro da geladeira (13\%) e piscina tratada com cloro (10\%) (FIGURA 3). Destacamos que a porcentagem das respostas demonstra que os alunos estão inteirados sobre a biologia do mosquito, visto que dados importantes sobre a biologia e a ecologia do vetor, como a aderência dos ovos na parede interna dos recipientes que acumulam água, ou o fato de que para a eliminação dos mesmos seria necessário escovar o interior desses recipientes e não apenas desfazer-se da água acumulada são raramente veiculados em campanhas ou observados nos textos dos livros didáticos (ARAÚJO,2016). 
Figura 3 - Os possíveis criadouros dos mosquitos, citados pelos alunos

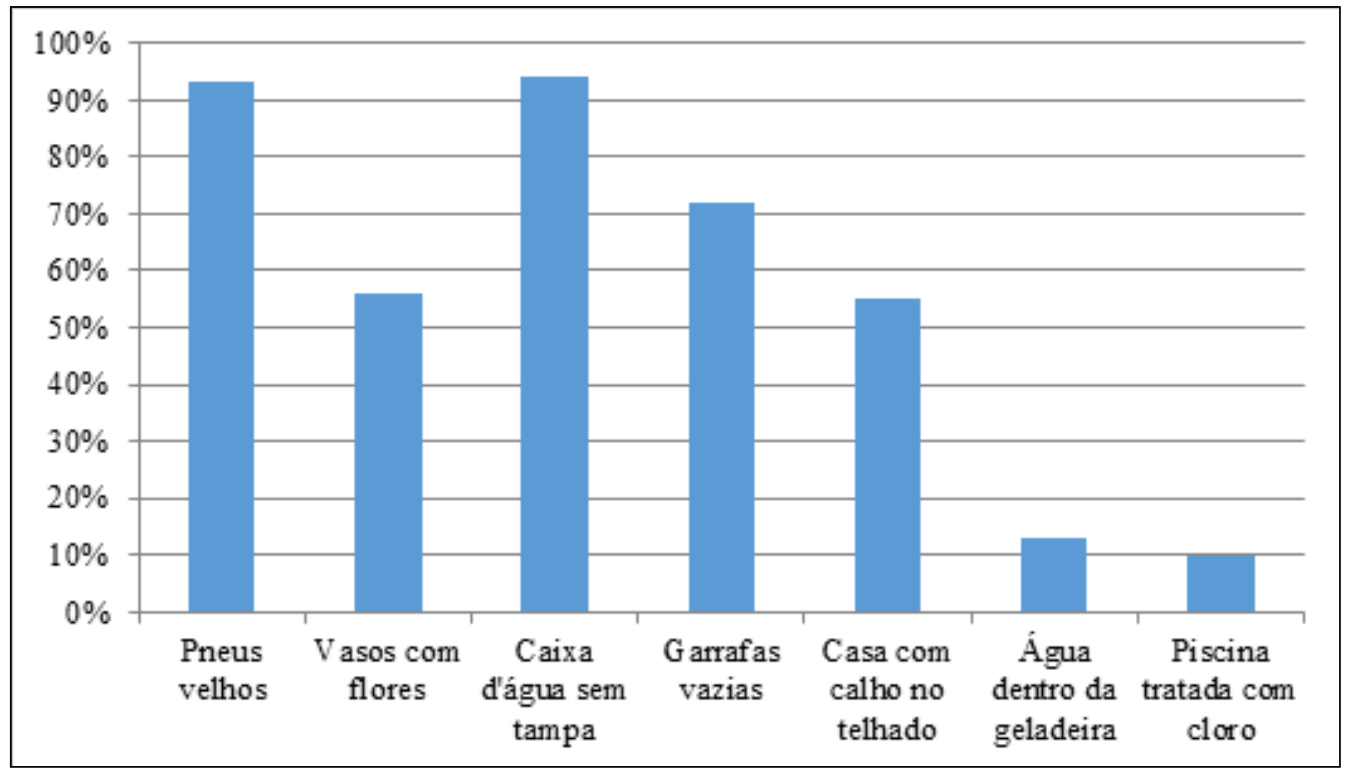

Fonte: dos autores.

Outro questionamento realizado foi sobre os cuidados que devem ser tomados para evitar a Dengue, Zika e Chikungunya. Nessa pergunta, 93\% alunos marcaram "usar repelentes", 89\% responderam "eliminar ou tampar os recipientes com água", 87\% "limpar os recipientes que contenham água", 73\% "usar telas e mosqueteiros", $36 \%$ "lavar as mãos" e 16\% "tomar Tylenol". No que diz respeito à dengue, além das alternativas de prevenção, foi recentemente uma alternativa para o tratamento, trata-se da vacina Dengvaxia, que começou a ser oferecida no fim de julho de 2016, no Brasil (TABAKMAN, 2016). Para a Chikungunya ainda não existe tratamento específico, nem vacina disponível para prevenir a infecção pelo vírus, sendo que a principal forma de prevenção é manter o domicílio sempre limpo, eliminando os possíveis criadouros, usar repelentes e inseticidas seguindo as instruções do rótulo, usar mosquiteiros e telas para proteção. Além disso, é importante destacar as demais marcações, como lavar as mãos e tomar Tylenol. A ação de lavar as mãos não está, necessariamente, ligada com os cuidados indicados para se evitar tais doenças, podendo sim prevenir o indivíduo de adquirir bactérias e microrganismos que podem gerar outros tipos de enfermidades. No que se refere ao consumo de medicamentos sem prescrição médica, alertamos para o perigo dessa prática e destacamos que cabe aos pais, coibi-la, evitando assim, problemas futuros. 
Figura 4 - Cuidados que devem ser tomados para evitar a Dengue, Zika e Chikungunya

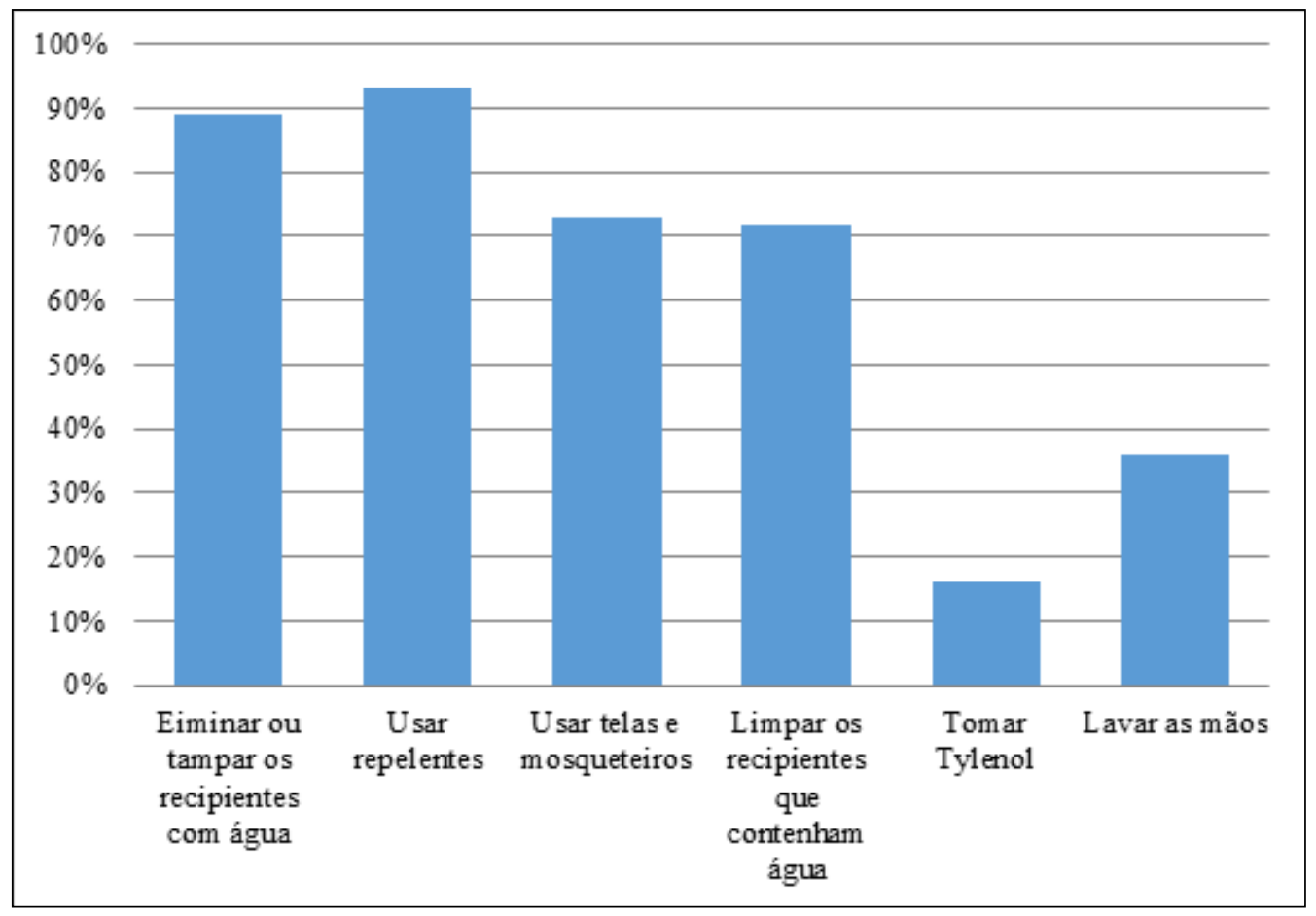

Fonte: dos autores.

Ao perguntar aos alunos sobre quem deve combater o mosquito transmissor dessas viroses, $92 \%$ responderam a população, $18 \%$ responderam o governo, $10 \%$ responderam escolas e universidades, 30\% marcaram o sistema de saúde e 5\% não souberam responder. Vivemos em sociedade, onde cada cidadão tem o dever de cuidar do ambiente, sejam nas empresas, hospitais, escolas, casas ou outro local. Seja o Poder público, instituições privadas ou a própria população, todos precisam trabalhar juntos e fazer sua parte, para que assim haja um ambiente equilibrado para toda a sociedade.

O Programa de Erradicação do Aedes aegypti no Brasil (PEAa) propõe que o agente de saúde, que há décadas trabalha para a comunidade, passe agora a trabalhar com a comunidade. Esta mudança, se bem conduzida, fará com que a população com a comunidade perceba que o combate ao Aedes aegypti não é só um "programa do Ministério da Saúde" e sim, uma atividade de interesse comum (FUNASA, 2001). Tauil (2001, p. 101) explica que "as ações de prevenção da dengue necessitam de envolvimento de outros setores da sociedade, particularmente na questão da melhoria das condições de urbanização e de habitação, coleta regular de lixo, abastecimento permanente de água encanada e educação escolar”. Já Penna (2003, p. 288) afirma que "em termos práticos, temos de distinguir o que deve ser normalizado e fiscalizado do que deve ser executado diretamente pelo poder público". 
Figura 5 - Quem deve combater o mosquito transmissor dessas viroses

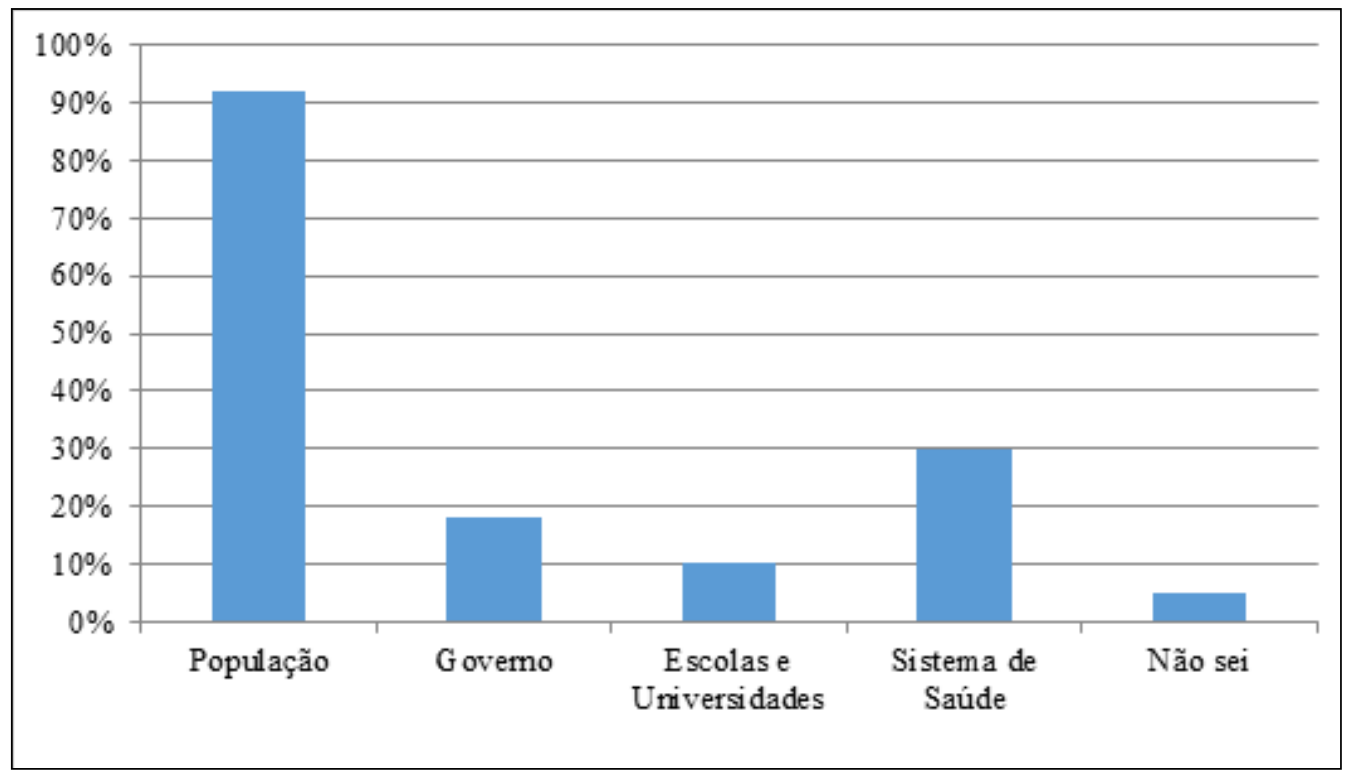

Fonte: dos autores.

Quando perguntados se já houve casos de uma das três viroses (Dengue, Zika e Chikungunya) em sua residência, obteve-se: $62 \%$ responderam sim, $26 \%$ responderam não e $12 \%$ não souberam responder. Dos que responderam sim, $61 \%$ foram casos de Zika, $18 \%$ de Dengue e 33\% de Chikungunya, sendo que em 13\% dos casos houve mais de uma doença (FIGURA 6). De acordo com as respostas podemos supor que pode ter tido ocorrência de uma das viroses nas residências dos alunos, porém não se pode afirmar ao certo se as doenças ditas foram correspondentes com a realidade, visto que não temos informações se essas pessoas foram diagnosticadas contendo o vírus equivalente à virose mencionada. 
Figura 6 - Casos de alguma virose na família

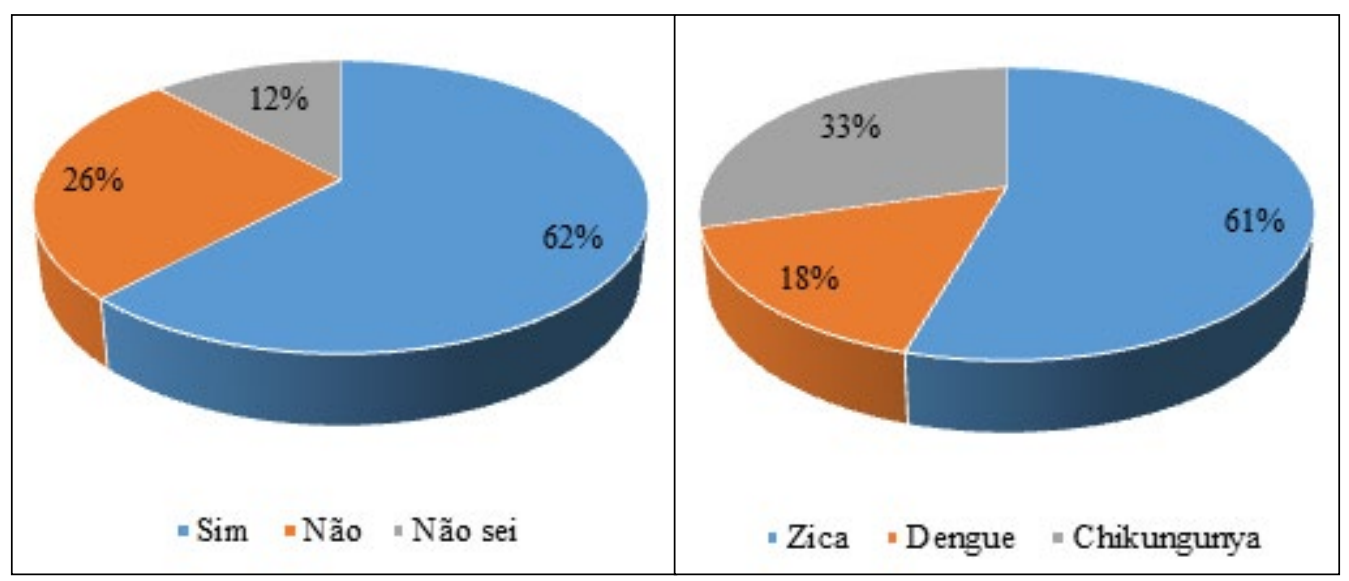

Fonte: dos autores.

Questionados sobre a eficácia das campanhas educativas, $86 \%$ dos alunos responderam que são eficazes, $6 \%$ afirmaram que não e $8 \%$ não souberam responder (FIGURA 7). Segundo Claro et al. (2004) é reconhecida, hoje, a importância que o acesso às concepções populares sobre as doenças têm para as estratégias de controle das mesmas. É importante que as campanhas educativas cheguem até as escolas, pois são lugares detentores de informação, além de que é bom ressaltar aos alunos como prevenir e evitar essas doenças, bem como combater os criadouros do vetor. Brassolatti e Andrade (2002) defendem que as crianças, e especialmente os estudantes, formam classicamente, um excelente canal para a introdução de novos conceitos na comunidade, pelo fato de serem membros permanentes desta, e por estarem com o cognitivo em formação. 
Figura 7 - Sobre a eficácia das campanhas educativas para combater a Dengue, Zika e a Chikungunya

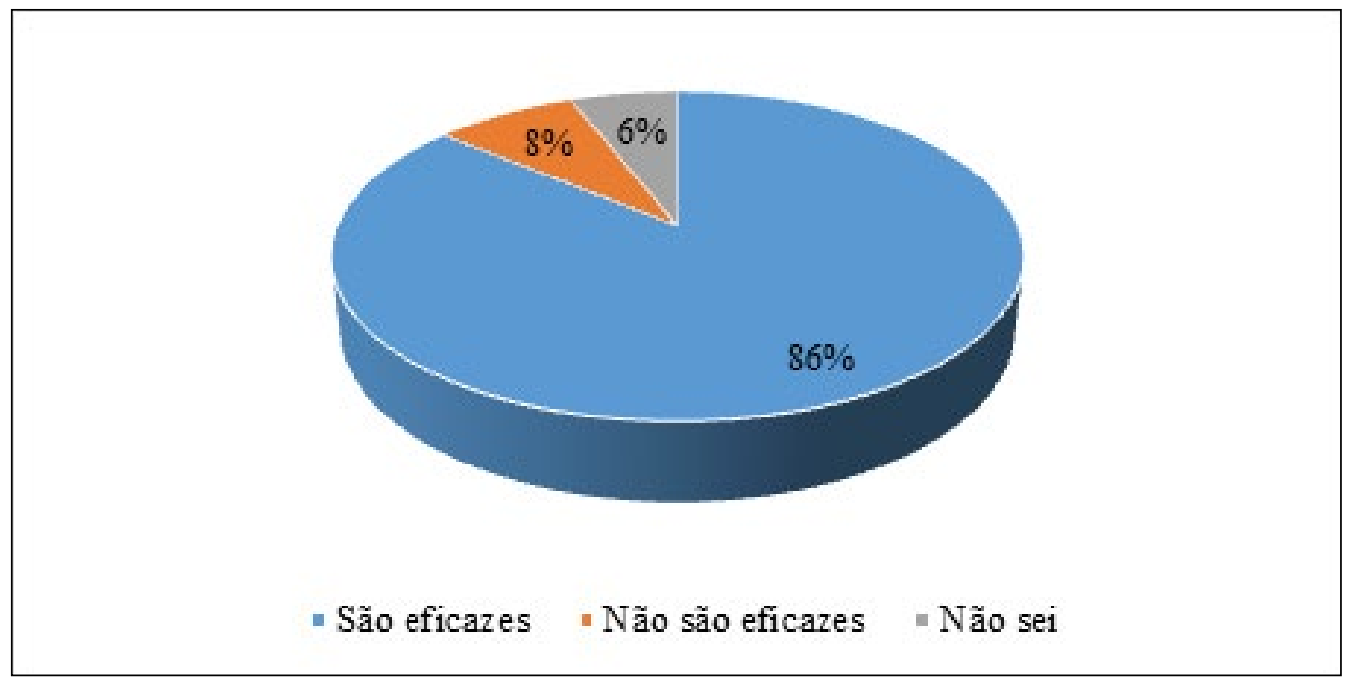

Fonte: dos autores.

Uma das questões perguntava se a escola desenvolve alguma ação contra a Dengue, a Zika e a Chikungunya, $64 \%$ alunos responderam que não, $20 \%$ responderam que sim e 16\% não souberam responder (FIGURA 8). Ao dialogar com a supervisora e com a professora de Ciências, a equipe foi informada que até o momento a escola não havia realizado ações contra as doenças, pois deveriam seguir o calendário já programado.

Figura 8 - A escola tem desenvolvido alguma ação contra a Dengue, a Zika e a Chikungunya

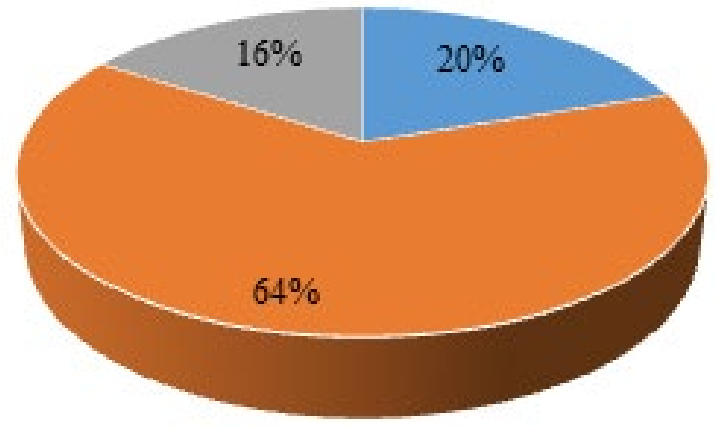

- Sim "Não " Não sei

Fonte: dos autores. 
Ao serem perguntados sobre o descarte de resíduos, 92\% responderam que o descarte incorreto contribui para a proliferação do mosquito $A$. aegypti e $8 \%$ responderam que não, indicando que a maioria dos alunos tem consciência que $o$ descarte incorreto de resíduos facilita a formação de possíveis criadouros do mosquito. Como relata Tauil (2001, p.100), "o sistema produtivo industrial moderno produz uma grande quantidade de recipientes descartáveis, entre plásticos, latas e outros materiais, cujo destino inadequado, abandonados em quintais, ao longo das vias públicas, nas praias e em terrenos baldios, também contribui para a proliferação do inseto transmissor do dengue". A autora relata ainda que "as mudanças demográficas ocorridas nos países subdesenvolvidos, a partir da década de 60, consistiram em intensos fluxos migratórios rurais-urbanos, resultando num 'inchaço' das cidades. Estas não conseguiram dotarse oportunamente de equipamentos e facilidades que atendessem às necessidades dos migrantes" (TAUIL, 2001, p. 100), ou seja, o grande crescimento populacional gerou ocupação de terrenos, consequentemente maior produção de resíduos a serem descartados e a coleta destes resíduos muitas vezes é falha e inexistente em alguns locais. Juntos, esses fatores potencializam a reprodução do vetor.

Figura 9 - Jogar lixo de forma errada contribui para o aumento da reprodução do mosquito

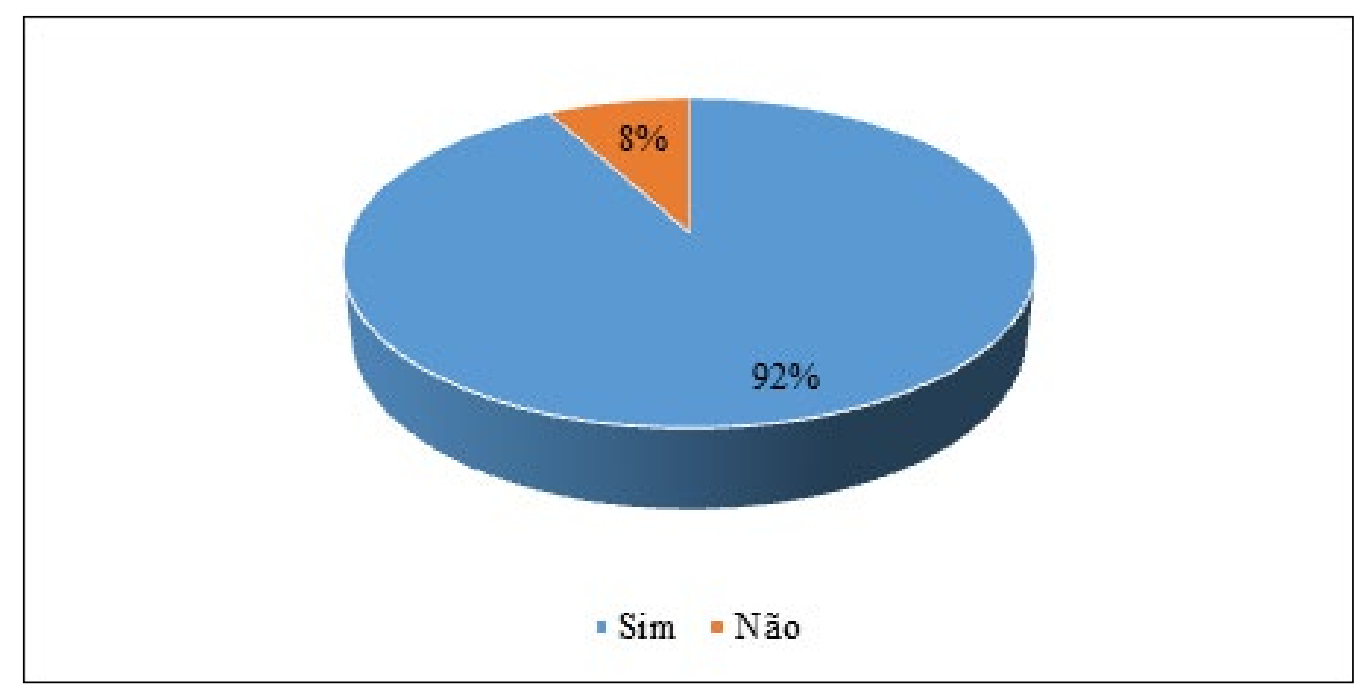

Fonte: dos autores.

\subsection{O mosquito por outras lentes - observação da morfologia do mosquito através de microscópios}

É de extrema importância a realização de aulas práticas nas diferentes modalidades de ensino e áreas do conhecimento, pois permitem aos alunos desenvolver o pensamento científico e crítico sobre a realidade em que vivem além de servir de auxílio para o professor complementar um assunto trabalhado em sala de aula. Estas não devem, 
necessariamente, se limitar aos laboratórios, mas utilizar também espaços que se insiram na realidade do estudante. Segundo Hodson (1998) as aulas práticas podem abranger técnicas mais inovadoras e tecnológicas. Já Araújo (2011) afirma que, cabe aos educadores buscar constantemente diversificar suas aulas através de atividades que permitam ao discente refletir, propor soluções e construções que sejam mais criativas.

Durante a atividade prática, os alunos puderam observar lâminas do mosquito Aedes aegypti com o auxílio de um microscópio óptico. Acompanhando a visualização das lâminas, os alunos também foram informados sobre as características biológicas do mosquito e formas de prevenção. Foi facilmente perceptível o grande interesse dos alunos por essa atividade do projeto, visto que foi a primeira vez que os mesmos tiveram contato com um microscópio. Freire (1997) afirma que para compreender a teoria é preciso experienciá-la. A realização de experimentos, em Ciências, representa uma excelente ferramenta para que o aluno faça a experimentação do conteúdo, estabeleça a dinâmica e a indissociável relação entre teoria e prática, e dessa forma, exerça de forma eficiente o seu cognitivo.

Figura 10 - Atividade prática para observação da morfologia do mosquito Aedes aegypti

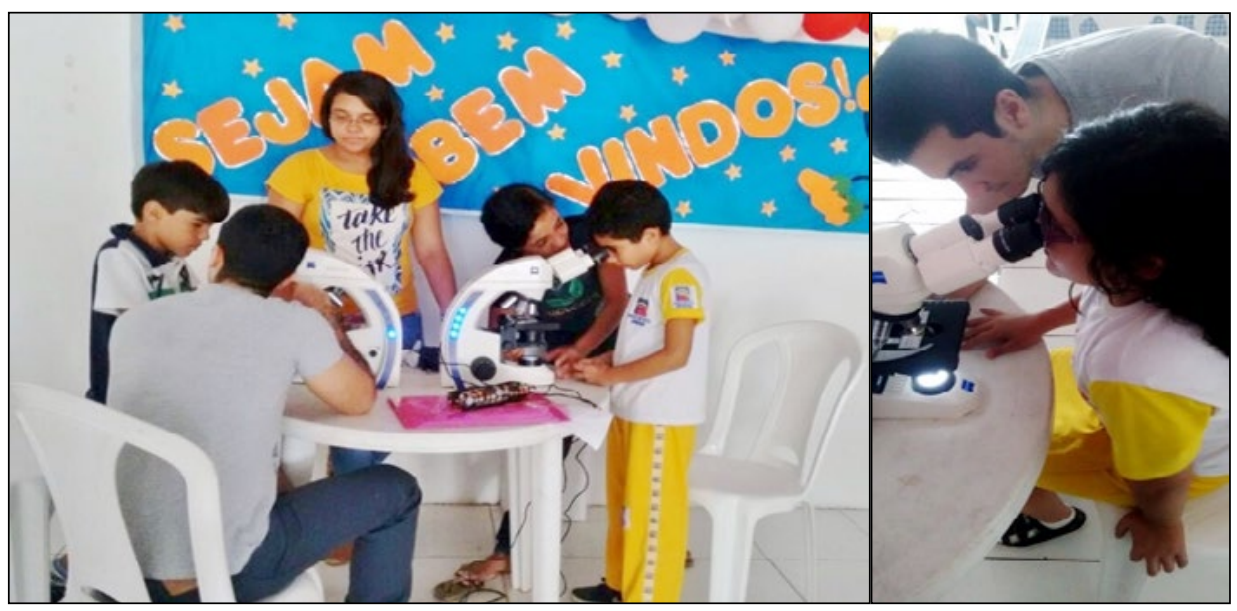

Fonte: dos autores.

Segundo Leite et al. (2008) o ensino de Ciências naturais vai fornecer uma relação intima entre a teoria e prática, com a visualização de células, plantas, animais, microrganismos e entre outros organismos observados no laboratório ou campo que podem despertar o interesse e a curiosidade do aluno; além de auxiliar o professor a retomar um assunto já abordado, construindo com seus alunos uma nova visão sobre um mesmo tema e permitindo que aquele conteúdo trabalhado em sala de aula seja compreendido com maior qualidade. Deste modo essa metodologia de ensino, permite que o aluno seja, de forma dinâmica, envolvido por uma inquietude cientifica que o faz problematizar, elaborar hipóteses e tentar solucionar as questões que o envolvem,tendo como resultados um aprendizado muito mais eficiente. 
Para Delizoicov, Angotti e Pernambuco (2002), os resultados científicos obtidos na academia ainda são pouco acessíveis à maioria do público escolarizado, e, por isso, passíveis de uso e compreensão acríticos e ingênuos. Sendo assim, é necessário pensar metodologias que induzam os alunos a incorporarem seu cotidiano a ciência como parte da sua cultura. Araújo (2011) enfatiza que os educadores devem buscar diversificar suas aulas através de atividades que permitam aos alunos refletirem e proporem soluções e construções criativas acerca de questões práticas do seu cotidiano.

Essa metodologia promove uma maior participação dos alunos em relação ao projeto. Durante a atividade eles realizaram questionamentos sobre o mosquito, as viroses e seus sintomas, além de citarem casos de familiares que foram atingidos por essas doenças. Também foi possível explorar seus conhecimentos prévios, através do qual se constatou ideias ainda muito arraigadas ao senso comum.

As aulas práticas podem ajudar no desenvolvimento de conceitos científicos, além de permitir que os estudantes aprendam como abordar objetivamente o seu mundo e como desenvolver soluções para problemas complexos (LUNETTA, 1991). Quando compreende um conteúdo trabalhado em sala de aula, o aluno amplia sua reflexão sobre os fenômenos que acontecem à sua volta e isso pode consequentemente, gerar ricas discussões durante as aulas.

Obteve-se como resultado, uma participação mais efetiva dos alunos e, portanto, um maior aprendizado e esclarecimento sobre a temática trabalhada. Borges (2002), afirma que as aulas práticas no ambiente de laboratório podem despertar curiosidade e, consequentemente, o interesse do aluno, visto que a estrutura do mesmo pode facilitar, entre outros fatores, a observação de fenômenos estudados em aulas teóricas. Nessas aulas, os alunos têm a oportunidade de interagir com as montagens de instrumentos específicos que normalmente eles não têm contato em um ambiente fora da sala de aula.

No entanto, Krasilchik (2008) argumenta que a falta de tempo para preparação de um material adequado aliado a insegurança no controle da sala de aula, são os principais motivos para a ineficaz difusão das aulas práticas nos dias atuais. Mas, apesar de tudo, reconhece que o entusiasmo, o interesse e o envolvimento dos alunos compensam qualquer professor pelo esforço e pela sobrecarga de trabalho que possa resultar das aulas práticas.

Portanto, as aulas práticas são também uma boa forma de verificar e auxiliar o processo de ensino-aprendizagem, uma vez que ao acompanhá-lo, é necessário passar pela observação dos progressos e das dificuldades da sala de aula. É uma atividade importante que o professor deve fazer, até para facilitar a compreensão dos os alunos que muitas das vezes têm dificuldade de entender o porquê dos conteúdos estudados em sala de aula (BIZZO, 2000). 


\subsection{Apresentação do vídeo "O mundo macro e micro do mosquito Aedes aegypti” como ferramenta pedagógica para a sensibilização dos alunos}

Entendemos que o uso de mídias é uma importante ferramenta pedagógica onde o processo de aprendizagem pode ser garantido de forma íntegra, possibilitando aos alunos acesso a informação de forma clara e objetiva. As novas tecnologias adotadas no ambiente da sala de aula são ferramentas poderosas para o ensino e aprendizagem da comunidade escolar envolvida.

Figura 11 - Apresentação de vídeo didático aos alunos

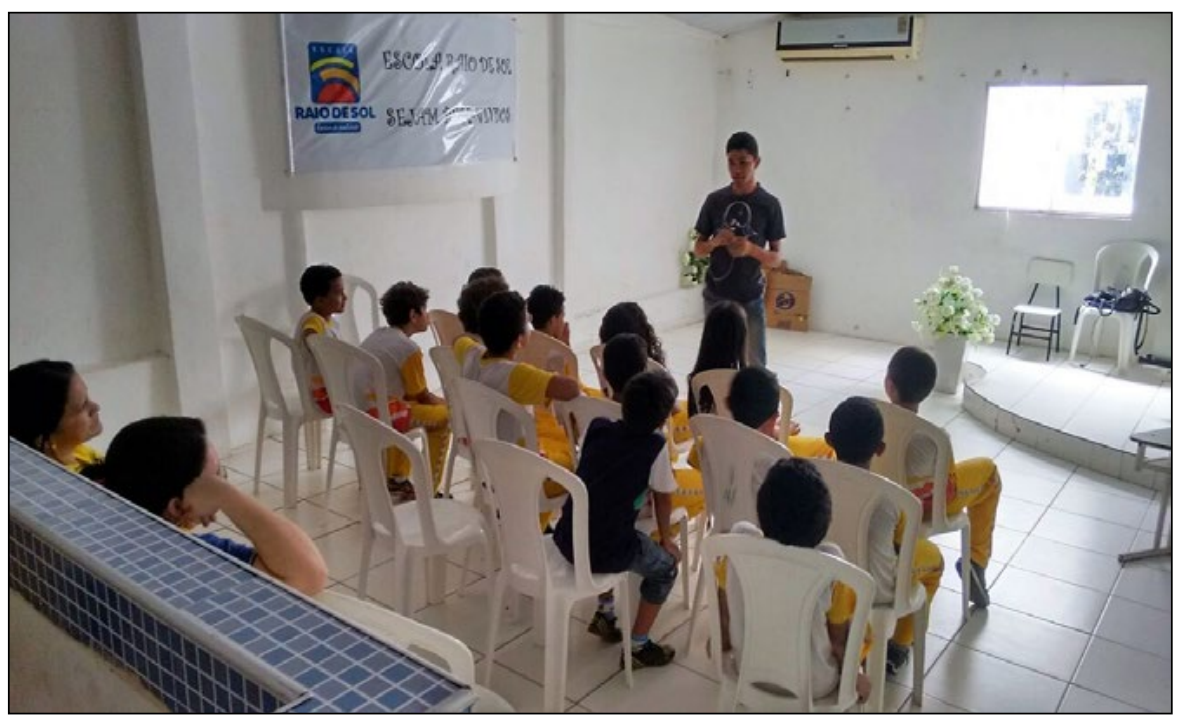

Fonte: dos autores.

O conceito de tecnologia adotado neste trabalho é apresentado por Kenski (2007) onde a mesma afirma que a tecnologia é um conjunto de conhecimento e princípios científicos que se aplicam ao planejamento, a construção e a utilização de um equipamento e em determinado tipo de atividade. Percebemos que nesse conceito pode ser incluída a mídia vídeo, por meio do qual, os alunos são levados a perceber situações e compartilhar conhecimentos, estimulando o pensamento crítico de cada um.

O vídeo como tecnologia educacional tem se destacado nos últimos anos e ganhado espaço como ferramenta que pode ser utilizada por professores de diversas disciplinas. Segundo Moraes e Torres (2004) essa estratégia de ensino fornece uma aprendizagem que possibilita a integração em vários sentidos: imaginação, intuição, colaboração, entre outros. Os mesmos destacam ainda uma agregação sofisticada em relação ao processo ensino-aprendizagem, na medida em que proporcionam a vivência e a interatividade, conectando sentidos, sentimentos e razão. 
Um dos primeiros autores a destacar a importância dos vídeos foi Moran (1994), escrevendo sobre a importância destes como ferramenta pedagógica na comunidade escolar brasileira. É notório destacar que as mídias desempenham ações benéficas ao aprendizado de diversas disciplinas do cotidiano escolar. Mas essa realidade sofreu entraves nos primeiros anos de inserção, alguns dos quais perduram ainda hoje. Muitos professores não utilizam vídeos em suas aulas por acharem que os alunos não darão atenção necessária a aprendizagem; ou as vezes, por falta de estrutura da própria escola, que não dispõe dos aparelhos necessários para uma boa vídeo-aula. Trabalhar vídeos com os alunos do Ensino Fundamental maior da escola Raio de Sol, apresentou resultados satisfatórios quanto a aprendizagem dos alunos. Percebeu-se o quão positiva foi essa atividade, pois, além de fornecer novas informações aos participantes, permitiu a também, a discussão do tema entre eles. Acreditamos que o vídeo se tornou uma ferramenta autoexplicativa, capaz de demonstrar aos alunos, de forma clara, a complexidade das viroses transmitidas pelo mosquito.

Pensando na inserção dos vídeos ao cotidiano escolar Moran (1994) afirma que a integração entre aula e vídeos não alterou as relações cotidianas na sala de aula, pelo contrário, gera-se a criação de novas questões, olhares e críticas construtivas durante o processo de aprendizagem.

A escolha do vídeo para este estudo remonta á questões que definem sua utilização como material didático apropriado. Segundo Ferrés (1998) alguns critérios definem a utilização de vídeos em sala de aula:

1) Usar vídeo como recurso audiovisual não significa abandonar os meios didáticos tradicionais, porém segue um redirecionamento da função destes. Um bom uso dos recursos didáticos na prática pedagógica, seja de tecnologias avançadas ou tradicionais, deve levar em consideração as condições e atributos de cada meio, a adequabilidade ao conteúdo e as características do aluno;

2) A inserção de um determinado recurso audiovisual deve estar voltada a impulsão do processo, tendo como centro, o aluno. Caso contrário, o vídeo torna-se um mero ilustrador do discurso do professor.

3) Quanto mais acesso o aluno tiver à tecnologias do vídeo no sentido de manipulála criativamente, pesquisar, fazer experiência que permitam a descoberta de novas formas de expressão, maior será a eficácia didática desse recurso.

Ao se analisar os diversos critérios propostos por Ferrés (1998) percebe-se que os resultados são bem visíveis e com um retorno positivo por parte dos alunos. Destacamos que nesse trabalho esses três foram contemplados. A exemplo, tem-se no item um, destaque para o uso do vídeo à adequabilidade do conteúdo, aspecto que prezamos na escolha do tema do vídeo apresentado aos alunos. Questões como "será que o conteúdo é adequado ao público a que se destina?” e "o conteúdo por meio da utilização desse vídeo será assimilado?” nortearam a utilização dessa mídia no presente estudo. 
No critério dois, reconhecemos o aluno como centro, por acreditar que sua participação na utilização dessa mídia seja de extrema importância, pois nos possibilitou reconhecer de que forma o conteúdo estava sendo assimilado, e se realmente os objetivos a que se destina a utilização dos vídeos foram alcançados.

Por fim, destacamos no critério três a importância do aluno, quando este tem acesso a tecnologia do vídeo, e assim, têm a oportunidade de aprender nessas mídias novas formas de expressão. Nesse ponto, a escola na qual o estudo foi realizado obteve destaque. Verificamos que os alunos já tinham contato prévio com as mídias, mas destacamos a necessidade de propiciar aos mesmos uma dinâmica de aprendizagem que inclua a utilização desse recurso, já que foi percebida a interatividade, a percepção e concepção de ideias desses alunos quanto à utilização do vídeo.

Reforçamos ainda que esse processo metodológico possibilitou-nos obter resultados semelhantes ao que foi encontrado por Lima et al. (2008) quando afirmam que as tecnologias educacionais são mecanismos que facilitam o aprendizado do aluno, dinamizando a aula, e o ambiente escolar, que limitava-se ao uso da lousa, giz e voz do professor, e agora dá espaço a um leque de possibilidades educativas, contempladas com a junção de recursos tecnológicos e planejamento coerente com a realidade vivenciada.

Dessa forma a utilização de mídias são ferramentas antes de tudo, exploratórias, pois permitem aos educadores e gestores analisarem o desempenho na aprendizagem de seus alunos frente à inserção dessas tecnologias, permitindo o trabalho do emocional, a construção da visão social dos alunos, bem como suas sensações acerca dos temas trabalhados em vídeos.

Portanto, acreditamos na natureza pedagógica dos vídeos, como ferramenta no processo de ensino-aprendizagem dos alunos do ensino fundamental frente atemáticas viroses emergenciais. Percebe-se ao longo deste estudo que a utilização do vídeo despertou nos alunos o interesse pela temática abordada. Foi notória a participação ativa de cada aluno ao questionarem sobre informações contidas nos vídeos e na resolução de cada pergunta elaborada com base no conteúdo audiovisual. Os vídeos foram nessa ação de pesquisa o recurso didático que gerou transformação de atitudes, pensamentos, críticas construtivas, possibilitando aos alunos uma dimensão nova do exercício intelectual, gerando, sobretudo, uma nova forma de agir e de construção do conhecimento.

\section{CONCLUSÃO}

Ao final do projeto podemos concluir que as informações sobre o mosquito Aedes aegypti e sobre as doenças a ele associados começam a ter destaque no contexto escolar. Os alunos demonstraram conhecimento sobre o tema, evidenciado que o mesmo tem sido discutido em sala de aula. Isso também demonstra um processo de divulgação eficiente acerca das doenças transmitidas pelo mosquito e das formas de evita-la. 
Percebeu-se o maior interesse dos alunos em aulas práticas e metodologias alternativas, as quais demonstraram ser mais eficientes no processo de conscientização e sensibilização dos mesmos. Portanto, essas metodologias devem ser incentivadas para que a educação possa contribuir no combate do mosquito dentro e fora do ambiente escolar.

\section{REFERÊNCIAS}

ARAÚJO, D. H. de S. A Importância da Experimentação do Ensino de Biologia. 2011. ix, 15 f. Monografia (Licenciatura em Ciências Biológicas) - Universidade de Brasília, Brasília, 2011.

ARAÚJO, I. C. N.; ARAUJO-JORGE, T. C. de; MEIRELLES, R. M. S. de. Prevenção à dengue na escola: Concepções de alunos do ensino médio e considerações sobre as vias de informação. V Encontro Nacional de Pesquisa em Educação em Ciências - ENPEC. Associação Brasileira de Pesquisa em Educação em Ciências. Atas do VENPEC.n.5. 2005.

AZEVEDO, J. B. Análise do ciclo biológico do Aedes aegypti (Diptera: Culicidae) exposto a cenários de mudanças climáticas previstas pelo IPCC (Intergovernmental Panelon Climate Change). 2015. 53 f.. Dissertação (Ciências Biológicas (Entomologia)) - Instituto Nacional de Pesquisas da Amazônia, Manaus, 2015.

BIZZO, N. Ciências: fácil ou difícil? São Paulo: Ática, 2000.

BORGES, A. T. Novos rumos para o laboratório escolar de ciências. Caderno Brasileiro de Ensino de Física, v. 19, n. 3, p. 291-313, dez. 2002.

BRYANT, J. E.; HOLMES, E. C.; BARRETT, A. D. T. Out of Africa: A Molecular Perspective on the Introduction of Yellow Fever Virus into the Americas. PLoSPathog.v.3, n. 5, p.75.

BRAGA, I. A; VALLE, D. Aedes aegypti: histórico do controle no Brasil.[s.1]: [s.n]: 2007.

BRASIL. Ministério da Saúde. Prevenção e combate: Dengue, Chikungunya e Zika.

Disponível em:<http://combateaedes.saude.gov.br/pt/prevencao-e-combate\#>. Acesso em: 26 de junho de 2016.

BRASSOLATTI, R. C.; ANDRADE, C. F. Avaliação de uma intervenção educativa na prevenção da dengue. Ciência \& Saúde Coletiva, v. 7, n. 2, p.243-251, 2002.

CHIARAVALLOTI-NETO, F. Descrição da colonização de Aedes aegypti na região de São José do Rio Preto, São Paulo. Revista da Sociedade Brasileira de Medicina Tropical, v. 30, n.4, p. 279-285, jul/ago, 1997.

CHIEFFI, P. P. Algumas questões decorrentes da reintrodução do Aedes aegypti no Brasil. Cad. Saúde Pública, Rio de Janeiro, v. 1, n. 3, p. 385-387, set. 1985.

CLARO, L. B. L.; TOMASSINI, H. C. B; ROSA, M. L. G. Prevenção e controle do dengue: uma revisão de estudos sobre conhecimentos, crenças e práticas da população. Cad. Saúde Pública, Rio de Janeiro, v. 20, n. 6, p. 1447-1457, nov/dez, 2004. 
COSTA, F. S. et al. A importância da interface educaçãolsaúde no ambiente escolar como prática de promoção da saúde. Informe-se em promoção da saúde, v. 4, n. 2. p. 31, 2008.

COSTA, M. A. R. A ocorrência do Aedes aegypti na região noroeste do Paraná: um estudo sobre a epidemia da dengue em Paranavaí - 1999, na perspectiva da geografia médica. 2001. 172 f. Dissertação (mestrado) - Universidade Estadual Paulista, Faculdade de Ciências e Tecnologia, 2001.

DELIZOICOV, D.; ANGOTTI, J. A.; PERNAMBUCO, M. M. Ensino de Ciências: fundamentos e métodos. São Paulo: Cortez, 2002

DONALÍSIO, M. R; GLASSER, C. M. Vigilância entomológica e controle de vetores da dengue. Revista Brasileira de Epidemiologia. São Paulo, v.5 n. 3, dez 2002.

FERREIRA, M. L. B. et al. Manifestações Neurológicas de Dengue: estudo de 41 casos. Arquivos de Neuro-Psiquiatria, São Paulo, v.63, n. 2b, jun. 2005.

FERRÉS, J. Pedagogia dos meios audiovisuais e pedagogia com os meios audiovisuais. (in) SANCHO, Juana M. Para uma tecnologia educacional. Porto Alegre. Artmed. 1998.

FREIRE, P. Pedagogia da Autonomia. Rio de Janeiro: Paz e Terra, 1997

FUNASA. Dengue - instruções para pessoal de combate ao vetor: manual de normas técnicas. 3. ed. Brasília: Ministério da Saúde/Fundação Nacional de Saúde, 2001.

GOMES, A.C. Medidas dos níveis de infestação urbana para Aedes (Stegomyia) aegypti e Aedes (Stegomyia) albopictus em programa de vigilância entomológica. JESUS, v. 7, n. 3, p. 50. jul/set, 1998.

HODSON, D. Realização de trabalhos práticos além do laboratório. Revista Internacional de Educação em Ciências, v.20, n.6, p. 629-632, 1998.

IOC/FIOCRUZ. Dengue vírus e vetor. Disponível em:<http://www.ioc.fiocruz.br/dengue/ textos/longatraje.html>. Acesso em: 30 de dezembro de 2016.

KENSKI, V. M. Educação e Tecnologia: O novo ritmo da informação. Campinas: Papirus, 2007.

KRASILCHIK, M. Prática de Ensino de Biologia. São Paulo: Edusp, 2008.

LEITE, A. C. S.; SILVA, P. A. B.; VAZ, A. C. R. A importância das aulas práticas para alunos jovens e adultos: uma abordagem investigativa sobre a percepção dos alunos do PROEF II.Revista Ensaio. Minas Gerais, v.7, n. especial. dez. 2005.

LIMA, F. L. Risco de urbanização da febre amarela no Brasil. Fundação Universidade de Brasília - Brasília - DF. Caderno de Saúde, Rio de Janeiro, p. 378, 1985.

LIMA, M. et al. O impacto do uso das tecnologias no aprendizado dos alunos do ensino fundamental I, Pernambuco, [2008?]. Disponível em: <https:/www.ufpe.br/ce/images/ Graduacao_pedagogia/pdf/2007.2/o\%20impacto\%20do\%20uso\%20das\%20tecnologias\%20 no\%20aprendizado\%20dos\%20alunos\%20do\%20ensino\%20fundamental\%20i.pdf >. Acesso em: 07 de janeiro de 2017. 
LUNETTA, V. N. Actividades práticas no ensino da Ciência.Revista Portuguesa de Educação, v. 2, n. 1, p. 81-90, 1991.

MORAES, M. C.; TORRE, S.DE LA. Sentipensar: fundamentos e práticas para reencantar a educação. Petrópolis: Vozes, 2004.

MORAN, J. M. Interferências dos meios de comunicação no nosso conhecimento. Revista Brasileira de Comunicação. São Paulo, v. 07, p. 36-49,jul/dez 1994.

. Ensino e aprendizagem inovadores com tecnologias e audiovisuais e telemáticas.

In:______. MASSETTO, M. T.; BEHRENS, M. A. Novas tecnologias e Mediação

pedagógicas. Campinas: Papirus, 2000.

OLIVEIRA, M. M. Como fazer pesquisa qualitativa. Petrópolis: Vozes, 2007.

PENNA, M. L. F. Um desafio para a saúde pública brasileira: o controle do dengue. Cad.

Saúde Pública. Rio de Janeiro, v. 19, n. 1, p. 305-309, jan-fev, 2003.

POULIOT, S. H.; XIONG, X.; HARVILLE, E.; PAZ-SOLDAN, V.; TOMASHEK, K. M.; BREART, G.; et al. Maternal dengue and pregnancy outcomes: a systematic review. Obstet Gyneco 1Surv. v. 65, p.107-18, 2010.

REBÊLO, J. M. M. et al. Distribuição de Aedes aegypti e do dengue no Estado do Maranhão, Brasil. Cad. Saúde Pública, Rio de Janeiro, v. 15, n. 3, p. 477-486, jul/set, 1999.

TAKAHASHI, L. T. et al. O Aedes e sua onda. Biomatemática Campinas: IMECCUnicamp, 2003.

VASCONCELOS, P.F.C. Doenças pelo vírus Zika: um problema emergente nas Américas? Rev. Pan. Amaz. Saúde, v. 6, n. 2, p. 9-10, 2015.

TABAKMAN, R. Dengue: o que é preciso saber sobre a vacina disponível no Brasil.

Disponível em: <http://www.sbp.com.br/src/uploads/2016/08/vacina-Dengue_Medscape. pdf>. Acesso em: 12 de janeiro de 2017.

TAUIL, P. L. Urbanização e ecologia do dengue. Cad. Saúde Pública, Rio de Janeiro, v. 17, supl. p. S99-S102, 2001. 